\title{
4 \\ ON THE EVOLUTIONARY FUNCTIONS \\ OF THE SYMBOLIC SELF: \\ THE EMERGENCE OF SELF-EVALUATION MOTIVES
}

\author{
CONSTANTINE SEDIKIDES \\ JOHN J. SKOWRONSI
}

The human self-concept has captured the fascination and imagination of intellectuals from many walks of life-writers and poets, religious and political figures, philosophers and scientists. These intellectuals have described the self-concept as enigmatic and mysterious; the key to understanding the essence of human nature; the basis of motivation, emotion, and behavior; and the royal road to personal misery and societal woes.

Some of our previous theorizing has focused on the possible evolutionary bases of the symbolic self, the type of self-concept that is possessed by humans (Sedikides \& Skowronski, 1997; Skowronski \& Sedikides, 1999). it is

We thank several anonymous reviewers for their constructive comments on earlier versions of this manuscript. Correspondence concerning this chapter should be addressed to Constantine Sedikides at the Department of Psychology, University of Southampton, Highfield Campus, Southampton, S017 IBJ, England, UK, or at C.Sedikides@ soton.ac.uk. 
our contention that the symbolic self is a uniquely human attribute that is distinct from two other types of self-conceptions that occur in the natural world. The subjective self refers to an organism's capacity to differentiate crudely between the organism (the self) and the physical or social environment. This type of self-awareness is widespread: All living species are able to make this self-versus-environment distinction, which need involve only simple, implicit, and automatic mechanisms. These mechanisms allow organisms to respond to environmental stimulation and to engage in self-regulation.

In comparison, relatively sophisticated cognitive capabilities are essential to a second type of self-concept, the objectified self. An organism with objective self-awareness has the capacity to "become the object of its own attention" (Gallup, 1992, p. 117), to be "aware of its own state of mind" (Cheyney \& Seyfarth, 1992, p. 240), and to "know it knows; to remember it remembers" (Lewis, 1992, p. 124). This type of self-awareness is present only in a few species, such as chimpanzees, orangutans, and bonobos (Hyatt \& Hopkins, 1994; Suarez \& Gallup, 1981). However, even the relatively sophisticated cognitive abilities that underlie this form of the self-concept are not comparable to the cognitive abilities of human adults. Indeed, the objectified self is similar to the type of self-concept that human toddlers have in the age range of 15-24 months (Gallup \& Suarez, 1986).

The symbolic self possessed by human adults subsumes the other two types of self-concepts and requires far greater sophistication in cognitive capabilities than is required by the objectified self. More specifically, in our view, there are three aspects to the symbolic self. The representational aspect of the symbolic self refers to the representation of one's personality and characteristics (Higgins, 1996; KibIstrom \& Cantor, 1984; KibIstrom \& Klein, 1994) in the memory system. Mental representations that are relevant to the symbolic self contain many different kinds of information. These representations contain abstract, language-based representations of an individual's demographic, physical, trait, or behavioral attributes (Markus, 1983). Self-relevant mental structures also contain temporally organized semantic, episodic, and perceptual representations of an individual's personal history (Thompson, Skowronski, Larsen, \& Betz, 1996). Furthermore, self, relevant mental representations contain knowledge about goals, values, and feelings (Emmons, 1989); imagined, desired, or feared information in future or hypothetical contexts (Higgins, 1987; Kato \& Markus, 1993); information about possessions, social roles, and social relations; and beliefs about how others might perceive one's personality and characteristics (Belk, 1988; Shrauger \& Schoeneman, 1979).

The second aspect of the symbolic self refers to its executive functions (Baumeister, chapter 1, this volume; Breckler \& Greenwald, 1986; Cantor, Markus, Niedenthal, \& Nurius, 1986). The symbolic self is involved in and helps to guide information-seeking, goal-setting, and goal-directed behavior. As Baumeister (1998, p. 712) noted, "Without this active function, the self 
would merely be a passive spectator, aware of itself and related to others, but unable to do anything except perceive and interpret the flow of events and to experience emotions." Instead, the symbolic self helps an individual to experience agency: the desire to choose, to control, to have an impact on situations (although this desire may not always be present-see Skowronski $\&$ Carlston, 1982). This choice-making aspect of the symbolic self is often guided by perceived self-interest. Hence, this aspect of the symbolic self is implicated when potentially negative feedback is avoided, rationalized, derogated, or discredited (Taylor \& Brown, 1988). Similarly, it is partly because of this aspect of the symbolic self that favorable outcomes lead to uplifting psychological states (e.g., experiencing high self-esteem or pride), whereas unfavorable outcomes lead to deflating psychological states (e.g., experiencing shame, guilt, or embarrassment). In summary, the executive aspect of the symbolic self is involved in making choices, coping with feedback, and experiencing the emotional consequences of outcomes.

The third aspect of the symbolic self is its reflexive potential. In simple terms, this aspect refers to the capacity of the organism to be conscious of itself (Baumeister, 1998). However, this reflexive potential is often manifested in the interchange between the executive and representational aspects of the self. This interchange has its roots in the notorious malleability of the selfconcept. Many psychologists explain this malleability by hypothesizing that the self is not a single, stable entity. Instead, there may be a set of diverse self-representations that are stored in memory, and these diverse selves may not be well integrated. Hence, the self that one is experiencing at any given moment (the phenomenal self-concept) may simply be a reflection of the self-representation that is temporarily activated in working memory.

What determines the representation that is activated? We conjecture that different aspects of the symbolic self may be activated in accordance with the goals of the individual. That is, the elements of situations and the goals set by the executive system in those situations may contribute to the activation of a given self-representation, and thus they can cause perceptions of the self to vary across the situations (Markus \& Kunda, 1986; MeGuire, McGuire, \& Winton, 1979).

Furthermore, the guidance provided by this temporarily activated selfknowledge is dynamic in that it can affect the processing of self-relevant information and the subsequent storage of this information (Showers, 1992; Vallacher \& Nowak, chapter 2, this volume). Because different aspects of the self may be active at different times, the guidance provided by these aspects of the self can allow individuals to develop and store bodies of self-relevant information that are inconsistent with each other (Fazio, Effrein, \& Falender, 1981). Such flexibility may operate in the service of self-regulation. Others have already observed that the self has an extensive capacity for its own regulation, that is, for minimizing, maximizing, or overriding previous cogni- 
tive, affective, motivational, and behavioral processes (Carver \& Scheier, 1990; Higgins, 1996).

TO summarize, then, current thinking about the symbolic self suggests that it is a dynamic system containing multiple components. One key component of this system is storage: the essential library of an individual's past and present and the repository for an individual's goals and aspirations for the future. The second key component is regulatory: The symbolic self is a crucial originator, mediator, or moderator of an individual's thinking, feeling, and behaving. The third key component is flexibility: Both the sittia, tion and individual goals and aspirations can cause the phenomenal self to shift across time and situations by activating or deactivating components of stored self-knowledge.

The voluminous research that has arisen around the construct of the self in psychology attests to the importance of these aspects. However, one question that has remained relatively unexplored concerns the origins of the symbolic self. Why do humans have a symbolic self? Where did it come from? How did it evolve? Discerning the answers to such questions may further the understanding of some of the current characteristics of the symbolic self and may help us to fathom the functions that the symbolic self has in human life.

\section{THE SYMBOLIC SELF AS AN ADAPTATION: EVOLUTIONARY PRESSURES AND FUNCTIONS}

In our previous theoretical work, we addressed the possibility that the symbolic self is a biologically selected adaptation that evolved in response to the pressures of natural selection (Sedikides \& Skowronski, 1997; Skowronski \& Sedikides, 1999). In that work we argued that the symbolic self is a capacity that was selected and distributed in the human population because of its high adaptive value. In thinking about our ideas, it is important to note that we presuppose that the emergence of this capacity is relatively unique to the hominid evolutionary past. Many of the evolutionary pressures that we discuss in this chapter (the capacity to hunt, a social habit) would seem to apply equally to other species, such as lions. So why don't lions have a symbolic self? The answer is that evolution does not magically conjure traits from nothing-a trait must be present before natural selection exerts its effects. We are making the huge assumption that somewhere along the way a happy accident occurred: A mutation or a favorable mating produced hominid individuals with the capacity for a symbolic self, a capacity that has (so far as we know) as yet not emerged in the feline population.

Given the existence of a favorable, selectable trait in a population, to make an evolutionary argument one needs to identify the situational pressures that are responsible for the selection of the trait, and one must be able 
to understand how the selected trait helps overcome those pressures. Our analyses of alternative sources of evidence, including evidence from physical anthropology, the possible evolutionary timelines implied by that evidence, and evidence of the self in nonhuman species, led us to speculate that the evolution of the symbolic self was tied to two factors. The first of these factors was the emergence of symbolic reasoning capabilities, which were spurred, in part, by the unique problems that confronted individuals who were sometimes poorly equipped for the task of food procurement. The second of these factors was the socially oriented structure of early human life. It is our opinion that the development of cognition and high intellect set the cognitive foundation for the development of the symbolic self. However, in our view, this high level of cognition is not sufficient for the development of the symbolic self; the social habit of humans was also a critical determining factor. In the next sections, we review briefly each factor and discuss its synergistic relation (for more detail and empirical support, see Sedikides \& Skowronski, 1997).

\section{Ecological Pressures and the Cognitive Foundations of the Self}

One of the main story lines of human evolution follows the emergence of cognition and intellect. Current thinking among many students of human evolution suggests that the evolution of human thinking abilities was driven in part by difficulties in finding and procuring food. Survival and procreation rely on adequate procurement of food. If the food procurement environment is difficult, one can overcome the difficulty either by becoming more intellectually adept overall or by improving a specific cognitive ability related to food procurement.

The record of natural history and comparative biology makes a strong case that such a relation is plausible. For example, problems in foraging and finding food are linked with increased encephalization: The irregular (in time and space) distribution of food supplies is associated with larger brain-to-body ratios among frugivore primates (Milton, 1988). In addition, an animal's food procurement lifestyle is related to its intellective abilities: Omnivorous extractive foragers have the largest brain-to-body ratios among primates (Gibson, 1986). In short, then, one likely lesson from natural history is that either the entire intellect or aspects of the intellect are subject to selection pressures, and one of the important selection pressures is food procurement.

Some scholars in the area of evolution have argued that the intellectual abilities of human ancestral species were prime targets for the influence of natural selection, especially given their rather modest physical abilities. As Fox (1980) put it: "Very little about ... our ... forebears could have inspired confidence ... not the stature, the speed, the strength, the ferocity... And the answer to this ultimate success can only lie in the very helplessness of 
the original creature" (p. 175). Fox probably overstated the case. It may be more appropriate to hypothesize that the evolutionary ancestors of modem humans may sometimes have found themselves underequipped to deal with their environment-an opportune scenario for evolutionary change.

This ill fit could have been caused by a couple of factors. One is migration. One of the remarkable observations about humans is that they are widespread in distribution, occupying environments that range from icy cold to blistering hot. It is not difficult to imagine that survival is difficult and that an increased intellective capacity may be an advantage in these extreme environments. However, although the issue is still under debate, the evidence currently suggests that this wide distribution may have emerged relatively late in hominid evolutionary history. A second possibility is that the evolution of increased cognitive capacity was the consequence of environmental changes that prompted a shift in lifestyle. Although the exact status of the human lineage is under constant revision, some current thinking suggests that our human ancestors came from an arboreal background (e.g., Australopithecus ramadus) and only gradually made the transition to land-based bipedalism. One might guess that the arboreal origins of the early ancestral line were rather incompatible with life on the ground, especially given that this shift in environment may have also been related to a shift in lifestyle from a diet that relied mainly on plant material to one that included meat. In addition, recurring climactic changes (which may have prompted bipedalism in the first place) could have made food procurement even more difficult by spreading out food sources in time and space.

If evolution operates on the mind, then environmental pressures associated with food procurement could have worked to enhance several specific mental faculties. Locating and recognizing food sources requires enhanced categorization and memory processes. Searching for food requires enhanced spatial memory and cognitive mapping. Handling, processing, and storing food requires enhanced cognitive representation abilities and the capacity to anticipate future events. In addition, the challenges associated with hunting large and mobile animals could have further added to the evolutionary selection of mental abilities. Pursuit in hunting requires accurate perception of fast-moving targets, mental orientation and rotation, split-second recognition, rapid taxonomic memory, and the ability to act on quick or reflexive ( "gut feeling") responses. More important, these activities may have prompted the evolutionary emergence of symbolic reasoning. Approaching game closely and being competent in stalking require sophisticated planning and decision-making abilities. The ability to plan an optimal route of attack involves being able to remember or to imagine how prey might react to an attack. This ability to imagine and plan involves symbolic reasoning: the capacity to think about things by manipulating images or concepts. Similar skills are involved in tool construction and use. For example, excellence in flint-knapping requires a good deal of planning and imagination while work- 
ing the stone. Similarly, developing optimal shapes for the flints presupposes knowledge about the effectiveness of different shapes and how they can be used in hunting.

\section{Social Pressures and the Evolution of the Symbolic Self}

In addition to the possibility that problems in food procurement led to increases in cognitive ability, such increases may also have come from the social nature of human ancestors. The anthropological evidence suggests that human ancestors were social organisms living in extended family units or small groups (Isaac, 1981). From an evolutionary perspective, membership in such groups has its plusses and minuses. Among the benefits are improved predation (e.g., hunting efficiency, food sharing), reduction of predation risk, and cooperative defense of essential resources (e.g., food sources and mates) against rival groups.

Interestingly, one of the side benefits of group living is that it may be related to enhanced thinking prowess. In primate species, there is a strong positive relation between group size and brain size: Species that have a terrestrial lifestyle and that live in large groups have bigger brains than do other species (Dunbar, 1992, 1993). This relation appears to hold, even when one accounts for lifestyle differences, such as diet. A moment's thought will lead to the realization of why this relation may exist. Relationships with a single individual can be quite complex, and the more individuals there are with whom to interact, the greater the complexity will become. A good dollop of intelligence (or of social intelligence, if one is inclined to think in modular terms) helps to more effectively navigate the complexities of group life and can result in better reproductive fitness.

Let us elaborate on this point. One of the possible consequences of group living, especially in individuals with enhanced cognitive and memory capacities (which, as we have already argued, were emerging in human ancestor species) is the evolution of a complex social organization with numerous rules, roles, and patterns of relationships. This complexity can evolve for several reasons. One source of role differentiation comes from the different tasks that individuals in the group can perform. For example, in ancestral human species, labor was probably divided along gender lines (Tanner, 1983; Tooby \& DeVore, 1987). Men hunted for big game and protected the group against rival groups; women carried out the tasks of gathering food, preparing food, and caring for children.

However, other types of within-group differentiations can emerge. For example, group members can differ in social status, and these differences can contribute to the evolutionary pressures that may have caused the symbolic self to develop. It is important to note that in the cognitively flexible humans this status may not have taken the form of a simple dominance hierarchy of 
the type observed in many animal species---that would not put much pressure on the evolution of the symbolic self. Instead, more pressure would occur if humans maintained a relatively loose and flexible social structure in which status differentiation was somewhat flexible and dependent on circumstances. In such structures, one does not always know where one stands in the group. Instead, one must engage in numerous cognitive tasks to determine one's social standing. One must pay attention to the situation and remember how one interacted with a given subgroup at any point in time. In such groups, interaction and coordination pose a tremendously complex cognitive problem, and part of the solution to this problem might have been the eventual develop, ment of a symbolic self that could better keep up with rapidly changing situations, subgroups, and interactions.

The various elements of interactions that occur in these groups can increase this complexity. When in a group, one can experience various kinds of cooperative dyadic interactions (e.g., feeding, grooming, fighting), dyadic relationships (e.g., kinship, friendship), and intragroup interactions. Within, group cooperation presupposes role differentiation (i.e., well-defined roles maximize interactive goal attainment), coordination of individual effort, conformity with the majority of group members, group loyalty, and fear of social exclusion. All of these, again, can challenge an individual's intellective capacities. Furthermore, within-group cooperation can lead to coalition formation. The decision to enter or exit a coalition compels an elaborate and ever-changing cost-benefit analysis.

Intragroup interactions can also be characterized by competition, most notably intrasexual competition for suitable mates. This form of competition can place additional cognitive demands on the individual, such as remembering and recognizing relationships with other adults in the group (e.g., social rank), monitoring the rank of potential competitors, being capable of deceiving higher-ranked competitors, monitoring the sexual receptivity and fitness of potential mates, exhibiting physical and social prowess to attract potential mates, cheating, and detecting cheating. In addition, women need to safeguard against men's attempts at forced copulation. Finally, intergroup competition (e.g., maintaining a level of vigilance, defending offspring and territory, initiating hostilities at an opportune time) can also place demands on the cognitive system.

The natural history evidence suggests that the social pressures that are accompanied by a group lifestyle could have stimulated the development of the brain in human ancestral species. As was noted earlier in this chapter, group size in terrestrial primates is related to brain size. Furthermore, examination of casts of fossilized brains suggests that Broca's area was distinctly formed as early as Homo habilis. Thus, with the passage of time, communication skills were apparently becoming increasingly critical in the evolving hominids, a conclusion that is supported by the presence of other physiological changes in the fossil record. For example, an expanded and lowered 
pharynx, which is a physiological necessity for complex articulate speech, appears to have evolved by late Homo erectus.

Hence, we conclude that the social nature of the human ancestors probably contributed to the evolution of the brain, in both its enlargement and its differentiation. As we noted earlier in the chapter, similar effects were probably produced as a consequence of the ecological pressures experienced by human ancestor species. We propose that these ecological and social pressures worked synergistically toward the evolution of individuals who could engage in symbolic reasoning and who were habitually social.

In our view, the development of symbolic reasoning capabilities, the development of sophisticated communication capabilities, and the social context in which humans existed were the preconditions that set the stage for the evolution of the symbolic self. We note that we are not alone in this opinion. Other theorists, following similar lines of reasoning, have reached similar conclusions (Caporael, 1997; Caporael \& Brewer, 1991; Maryanski $\&$ Turner, 1992; Wilson \& Sober, 1994). The unique aspect of our own theoretical position is our emphasis on both social and nonsocial factors in the evolution of the symbolic self.

The adaptive utility of a symbolic self becomes evident if one considers the social and intellectual context experienced by human ancestor species members. We propose that the ability to construct a symbolic self led to enhanced functioning of the individual within the group and even enhanced the functioning of the group as a whole. For example, by becoming a communication referent, the symbolic self could have facilitated verbal and nonverbal exchanges among group members in various aspects of task performance (e.g., duty assignment during hunting expeditions, splitting of prey among group members, interchanging child-rearing tasks). Furthermore, the ability to construct and use a symbolic self could have allowed an individual to adopt the perspective of others in thinking about the self. This allows an individual to anticipate and influence how others might respond to one's own behavior, and it could contribute to an increased facility to handle the social dilemmas that invariably emerge when interacting with others. The use of a symbolic self could have facilitated decision making (e.g., joining maximal resource utility bands), goal setting (e.g., setting goals that matched the individual's capabilities), and behavior (e.g., withdrawing or aggressing depending on history of previous encounters with the antagonistic opponent). In short, we believe that the capacity to form and use a symbolic self added malleability, flexibility, and purpose to the individual's cognitive armamentarium and, by doing this, enhanced the adaptive fit between individuals and their environment.

The evolution of the capacity for a symbolic self may have had other effects as well. For example, the symbolic self can affect the nature of the communications that one has with others. To communicate with others, to enact social roles, and to influence others, an individual needs to possess 
knowledge of how to manipulate the presentation of self to others. Thus, these social processes can lead to the emergence of the public self. the self as presented to other group members. The public self, in rum, can contribute to the continued evolution of private self-knowledge through the process of reflected appraisal (i.e., seeing the self as important group members see the self) and through the incorporation of multiple group membership identities into the self concept. Our use of the plural in reference to group identity is important, for we assume that individuals need to have some flexibility in how group membership affects the self-concept. Such flexibility would be a seeming aid in groups in which roles are not rigidly fixed and in which alliances among subgroup's members are constantly shifting. Finally, the capacity to construct a symbolic self can ultimately have emotional consequences, because individual self-esteem can come to depend on the interpersonal evaluations provided by other group members.

\section{SELF,EVALUATION MOTIVES AND THEIR ADAPTIVE VALUE}

A logical next step in the argument that we have developed focuses on the acquisition of self-relevant information. If the construction and maintenance of a symbolic self is adaptive, then individuals will be especially sensitive to information that has implications for the symbolic self. Several lines of research attest to the power that self-relevant information has on human information processing (for a review, see Baumeister, 1998). Humans have a nonconscious processing sensitivity for self-relevant stimuli, are speedier in the processing of self-descriptive than self-irrelevant information, and better remember self-relevant than other relevant information. Furthermore, humans have better memory for material that has been self-referentially encoded than for material that has been encoded with reference to other people, and they remember self-generated material better than they do material generated by someone else. Moreover, the symbolic self exerts a strong effect on the processing of information about others. Humans selectively perceive and judge others on self-relevant dimensions: When these dimensions are central to the self, humans process the information deeply and draw a large number of (usually extreme) inferences

about others (e.g., Sedikides \& Skowronski, 1993). The self is also implicated in the choice of people with whom to affiliate. It is understandable, then, why Greenwald (1980) referred to the self as "the totalitarian ego."

However, in all of these cases, the perceiver is treated as a passive entity, as a mere information recipient. It should be obvious that humans are not simply information recipients, but they are also information seekers. Early hominid survival probably depended, in part, on the kinds of information sought and acquired from the environment, the way in which this in- 
formation was interpreted, and the way in which it was translated into judement and behavior. We hypothesize that this information-seeking tendency was applied to the symbolic self

What kind of information did our ancestors want and need to know about themselves? We speculate that several classes of information must be acquired to maintain the adaptiveness of the symbolic self. We further speculate that the symbolic self motivates the selective pursuit of some types of information over others and causes information searchers to filter out (or to facilitate the processing of) certain kinds of self-relevant information. Different motives may have evolved (or may have been adapted) to prompt the acquisition of these kinds of information.

Our analysis of the self-motivated information-seeking process relies on three classes of selfevaluation motives: valuation motives, learning motives, and homeostatic motives. The two valuation motives are self-protection and self-enhancement (Brown \& Dutton, 1995; Kunda, 1990; Tesser, 1988). The self-protection motive works to filter out, negate, or discredit information that is unfavorable to the self. The self-enhancement motive works to filter in, accept, and magnify information that is favorable to the self. The two learning motives are self-assessment (Sedikides \& Skowronski, 1995; Strube \& Roemmele, 1985; Trope, 1983, 1986) and self-improvement (Taylor, Neter, \& Wayment, 1995; Taylor, Wayment, \& Carrillo, 1996). The selfassessment motive refers to the pursuit of accurate self-knowledge, be it favorable or unfavorable to the self. The self-improvement motive refers to the pursuit of knowledge that can be used to improve the self, regardless of the negative short-term potential of this knowledge. The sole representative of the homeostatic motive category is selfverification (Lecky, 1945; Swarm, 1983, 1990). The self-verification motive refers to the pursuit or endorsement of information that is consistent with the self. Verification can apply to either negative or positive aspects of the self. Obviously, when the characteristics at issue are positive, it is difficult to determine whether the motive underlying information-seeking is verification or enhancement. It is this confound that explains why much of the empirical work addressing the selfverification motive has focused on verification of negative characteristics (e.g., Swarm, Wenflaff, Krull, \& Pelham, 1992).

The three classes of self-evaluation motives are widely held in the human population and are currently adaptive (Sedikides \& Strube, 1995, 1997). The naturalistic fallacy notwithstanding, we propose that the current adaptiveness of the motives constitutes a legitimate basis for exploring the possibility that the motives evolved in response to environmental pressures. More specifically, we consider the three classes of self-evaluation motives as secondary adaptations. We hypothesize that the role of these motives was to promote the adaptive value of the symbolic self and, in the long run, to better an individual's standing in the group, thus maximizing the chances for the individual's survival. 
Furthermore, we assume that the motives were modular and domain specific. That is, the motives served specific adaptive purposes in response to specific environmental problems (Buss, 1996). We propose that the motives evolved in response to individual-level and group-level adaptive problems and that the motives served cognitive, affective, and behavioral functions. At the same time, we assume interactive relations among the motives, and we will discuss a theoretical model that explicates these interactive relations.

Exactly when these motives began to serve the symbolic self is difficult to determine. Given that we have previously speculated that the symbolic self began to emerge in Homo erectus, it seems reasonable to hypothesize that the self-evaluation motives also began to emerge in that species. As we noted in Sedikides and Skewronski (1997), the Homo erectus species shows evidence of a large and differentiated brain and a speech production anatomy that could potentially concoct relatively elaborate vocalizations. However, neither of these was comparable to the more evolved anatomy of Homo sapiens. Furthermore, concrete evidence for symbolic thought (e.g., art, ornamentation) in the fossil record does not appear until after the emergence of Homo sapiens, with the possible exception of stone tools. Hence, perhaps it would be best to consider Homo erectus as the earliest possible species in which the symbolic self, and its associated motives, emerged.

Of course, there is no reason to believe that the symbolic self and its associated motives emerged fully formed. Instead, it is probably the case that the motives emerged gradually with the evolution of Homo sapiens and Homo sapiens sapiens. Given the importance of affect to human existence, it is reasonable to speculate that the valuation motives evolved first, followed by the learning and homeostatic motives. Furthermore, the motives may have initially emerged at the preconscious level and only later became a target of conscious awareness as the reflexive capacity of the symbolic self evolved. In fact, it is possible that our present treatise is mostly relevant to Homo sapiens sapiens rather than its predecessors. These are caveats of which we are aware, but we will not address them in the present chapter. Instead, we will proceed with our quixotic quest into the evolutionary utility of the self-evaluation motives.

\section{Valuation Motives}

There are numerous adaptive benefits that could have accrued from the presence of the valuation motives. Valuation motives can interact with the executive aspect of the self to affect choice,making activities. For ex, ample, valuation motives can lead individuals to avoid tasks with a high risk of failure (and hence, a threat to the symbolic self) and to select tasks on which success is likely (hence, bolstering the symbolic self). Of course, mere success may not have been the only criterion for task selection-it may also have been the case that maximum benefit for the symbolic self could have 
been obtained by selecting tasks that included an optimum combination of challenge and success probability. Protection or augmentation of the self could have been further achieved by the interaction of these valuation motives with the representational and reflexive aspects of the symbolic self- forgetting failures and remembering successes, making self-serving inferences and attributions, holding beliefs about the relative superiority of the self compared to other group members, engaging in downward social comparisons, and presenting the self advantageously to others. These strategies probably served affective functions, most directly the maintenance or enhancement of the individual's self-esteem. More specifically, the self-protection motive probably operated to maintain self-esteem, whereas the self-enhancement motive probably operated to heighten self-esteem.

Some measure of self-esteem seems to facilitate adaptive functioning: A relatively high level of self-esteem is associated with active engagement in everyday activities, planning, an optimistic attitude, improved coping, better psychological health (e.g., lower depression, anxiety, and loneliness), and better physical health (Ryff \& Singer, 1998; Taylor \& Brown, 1988). From an evolutionary perspective, one might surmise that some measure of self-esteem was necessary for an individual to initiate attempts at reproductive activity. It is also reasonable to guess that an individual who had some measure of self esteem had heightened appeal as a mate, thus improving the individual's chances of reproductive success. A happy, active, confident partner is an attractive partner.

However, this enhanced reproductive success may have occurred, in part, because it aided the individual in interactions with other group members. That is, the relatively high self-esteem promoted by the valuation motives may have facilitated both dyadic interactions and group-level interactions. A relatively high level of self-esteem can work to make an individual a more effective group member. For example, others in a group may view an individual with high self-esteem as a safe bet for the accomplishment of important group-wide tasks. $\mathrm{He}$ or she could be trusted to assume posts of increased responsibility within the group hierarchy. Hence, a reasonably high level of individual self-esteem may have maximized opportunities for advancement in the group hierarchy and minimized the possibility of social exclusion. Both of these outcomes could have improved an individual's chances for reproductive success in several ways. First, high group status was probably associated with successful mating. Second, the offspring of high status individuals were probably less likely to be neglected by the group as a result of social exclusion.

Some theorists have argued that natural selection operates not only at the individual level, but also at the group level (Wilson, 1998; Wilson \& Sober, 1994). If this idea is credible, (and we note that it is, currently, controversial), it may also contribute to the present argument. For example, one can also make a reasonable argument that, in the long run, the group itself 
benefited from the action of the valuation motives to produce relatively high self-esteem in group members. This high self-esteem could have promoted a high group activity level, a sense of group purpose and direction, and an aura of group optimism and morale, as well as the illusion of group cohesiveness under decisive leadership. Also, such high self-esteem could have made the group more effective in intra- and interspecies competitive encounters. High individual self-esteem in group members allows the group to engage effectively in both careful, protective planning (e.g., maintaining a climate of vigilance to thwart the possibility of hostile actions from others groups) and bold endeavors (e.g., daring hunting and gathering expeditions in the face of imminent danger from antagonistic groups), as needed.

\section{Learning Motives}

We have argued that the learning motives of self-assessment and selfimprovement serve to clarify and enrich the symbolic self. These could have been adaptive to human ancestor species members in several ways. The selfassessment motive could have contributed to the clarification of the representational aspect of the symbolic self via the executive aspect of the self. That is, individuals could have been motivated to pursue, choose, and construct tasks that were high rather than low in diagnosticity with respect to an underlying capacity. Because such high-diagnosticity tasks have the potential to provide a definitive test of whether the organism possesses an underlying capacity (a conclusion that is added to an individual's self-representational structure), they allow efficiency in later choices and time allocations.

For example, individuals may have deliberately selected tasks within particular domains (e.g., hunting, gathering, or child,rearing duties) that presented a challenge, that tested their abilities to perform within the domain. One result of such tests could have been increased veridicality of selfconceptions. This result has adaptive consequences. Individuals can use veridical self-knowledge in task planning to place themselves in environments whose demands match their abilities well, thus optimizing individual (and perhaps group) success. Hence, if an individual discovers that he or she has a good knack for discovering and gathering food, it would seem to be beneficial to both him- or herself and to the group to exploit this ability to its fullest.

Alternatively, if the results of high-diagnosticity tasks reveal that there is a deficiency in an area, then two courses of action are plausible. The first is the allocation of an individual's time to alternative pursuits. For example, an individual who is deficient at child-watching might be shifted to food gathering. In the second course of action, the self-improvement motive may be activated. Activation of this motive could prompt the individual to find ways to improve, such as engaging in practice, information gathering, and technological innovation. To the extent that these attempts at improvement 
were successful, they could have promoted individual and group fitness. For example, by becoming a better hunter, not only the individual, but also the whole group, may benefit. By aiding both themselves and the group, selfassessing and self-improving individuals could have enhanced their own reproductive fitness relative to a nonassessing and nonimproving counterpart.

The learning motives and their effects on the symbolic self could have increased the adaptiveness of the group, as well. For example, the learning motives were probably beneficial to group life. The self-assessment motive can promote the smooth functioning of the group, as its members gain a genuine knowledge of their hierarchical standing and of others' expectations of them. Furthermore, individuals can use veridical self-knowledge (e.g., accurate knowledge of their abilities) to place themselves in suitable and appropriate positions in the social hierarchy, thus minimizing disadvantageous conflict with conspecifics. For example, an individual with high social intelligence may effectively occupy the leader or counselor position in the group. Moreover, the self-improvement motive can increase the group's chances for survival by promoting trying. That is, the self-improvement motive can prompt the group to be persistent in its efforts to master challenges (e.g., increase the status of the group compared to groups of conspecifics) and create new ones (e.g., expand to new territory).

Finally, we propose that the learning motives may have served critical cognitive and affective functions for group members. For one thing, the selfassessment motive may have acted to reduce an individual's uncertainty about aspects of the self and aspects of the social or physical environment. In addition, the self-improvement motive could have worked to elevate an individual's sense of progress. This two-step benefit (i.e., a sense of self-certainty and progress-making) facilitates positive feelings of personal adjustment.

\section{Homeostatic Motives}

We have argued that the homeostatic motive of self-verification serves to stabilize the representational aspect of the self. The self-verification motive contributes to the stabilization of the self by numerous executive strategies that work toward the confirmation of existing self-views. These executive strategies include direction of attention to self-confirming information, bias in rehearsal and recall, solicitation of self-confirming feedback, biased interpretation of ambiguous feedback, biased causal inferences, and the prompting of self-confirming behavior.

We hypothesize that our hominid ancestors selected tasks (e.g., hunting, gathering, child-rearing) that were likely to confirm their preexisting competence beliefs. Furthermore, we think that the confirmation of selfattributes provided by these tasks rendered the social milieu more predictable and served the affective function of increasing feelings of control over the environment. This, in turn, cultivated a sense of personal efficacy. 
Such a sense of efficacy can be highly adaptive. Using such feelings of efficacy, an individual can make wise decisions about energy expenditure and can set goals that are congruent with the content of the symbolic self. This sense of efficacy can also be used to shift behavior so that it comes to be consistent with those goals. This pattern maximizes outcome success and, in the long run, reproductive fitness.

In addition, self-verification could have brought about favorable consequences for group life. Knowing his or her limitations, an individual may have sought and received confirming feedback from group members regarding social standing, roles expected from her or him, and the relative success with which these roles were carried out. This confirming feedback could have helped the individual to avoid the waste of energy that might accompany pursuit of a goal that is incompatible with group goals. Furthermore, this con, firming feedback had may have had affective consequences: It could have produced feelings of satisfaction and allowed the individual to avoid negative emotions (e.g., shame, guilt, and embarrassment). Moreover, the confirming feedback may have contributed to a stable internal structure of group governance and to the solidification of acquired resources (e.g., territory).

\section{THE PROCESS OF SELF-EVALUATION: AN INTEGRATIVE VIEW}

It would appear frorn our discussion so far that the self-evaluation motives and their corresponding functions would, more often than not, be in a state of friction. Would an individual be more likely to self-enhance or to self-assess? Would an individual opt to self-improve or to self-verify? Would an individual opt for self-esteem elevation or for uncertainty reduction? Would an individual opt for a sense of progress and growth or for a sense of control and predictability?

We propose that the self-evaluation motives did not operate independently in the prehistoric environment. Instead, the motives were dynamically interrelated and served complementary purposes. Furthermore, we propose that friction among the motives was the exception rather than the rule.

More concretely, we postulate that the self-evaluation process was carried out chiefly through the valuation motives (Sedikides \& Strube, 1997). To elaborate on this point, we distinguish between two types of self-enhancement, candid and tactical. Candid self-enhancement refers to flagrant attempts on the part of the individual to increase the positivity of the self-concept or to decrease its negativity. This type of self-enhancement is achieved either through brute self-aggrandization (e.g., ostentatious display of one's physical prowess) or through denial of clear wrongdoing (e.g., being caught subverting the dominance ranks). Tactical self-enhancement refers to indirect attempts to increase the positivity of the self or decrease its negativity. This type of self-enhancement is carried out through the learning and 
homeostatic motives. Its mannerisms are subtle, mindful of the balance between immediate and delayed rewards, and sensitive to social context.

We propose that the affective functions served by the self-evaluation motives followed a similar pattern. We have argued that self-enhancement increased self-esteem, that self-verification gave way to feelings of control, that self-assessment reduced uncertainty, and that self-improvement instilled a sense of progress. However, we do not view control, certainty, and a sense of progress as functions that the organism would necessarily seek for their own sake. Rather, these functions were critical to individuals because they were linked to the more basic desire for self-enhancement.

In addition, we argue that the self-evaluation process consisted of two components: information and action. The information component referred to the generation, refinement, and testing of hypotheses concerning the quality of the person-environment fit (e.g., "Am 1 strong enough to over, throw the higher-ranking group member?" "Can 1 hunt effectively with the weapons that 1 have?" "How can I use better child-rearing methods?"). This information reflects the extent to which the attributes or abilities of the individual match the demands of a given situation. The data that result from the information component can be used to carry out candid and, more often, tactical self-enhancement through action (e.g., coalition-building for bringing about change in the dominance hierarchy, striving to improve existing weapons or child-rearing practices). Thus, the action component pertains primarily to opportunistic responses to existing conditions or to the strategic creation of new conditions that could yield beneficial outcomes or bypass harmful ones.

Information and action are interdependent. In the prehistoric environment, to the extent that information about person-environment fit was veridical, likely to lead to improvement, and verifying of self-views, resulting actions were likely to be successful. Success was more likely because the individual was in a position to deliberately guide the creation of performance settings or to effectively manage the reaction to them; thus, the outcome was more self-enhancing than a less informed action. Likewise, the success of action probably provided crucial feedback about the validity of the action, the rate of improvement in behavior, and the verifying value of the information on which it was based.

When self-enhancement was carried out effectively through the information and action components (i.e., when the person-environment fit was successful), self-esteem, control, certainty, and a sense of progress would have been heightened for the individual. When this happened, the individual would have experienced the emotion of happiness. That is, we propose that the emotion of happiness would be produced when the organism fit environmental requirements and was also challenged adequately. Additionally, happiness can signal to the organism the effective operation of feedback loops among motives. For example, consider the case in which self-assessment 
leads to the reduction of uncertainty, which itself sets the stage for self, improvement. In rum, self, improvement, the outcome of successful learning, instills a sense of progress that increases perceptions of control. This fuels organismic, activity, giving way to the elevation of self-esteem. The resulting emotion is happiness. In summary, we speculate that one of the functions that happiness came to serve was as the overflow emotion, a check that the motives and their functions were in symbiotic relation with each other.

In our view, then, self-esteem consequences were probably the most immediate outcomes of the self-enhancement process and provided the essential gauge regarding the utility of the individual's actions for the group (e.g., Did the group approve of the organism? Should the organism persist along the same path or redirect action instead? See Leary, Tambor, Terdal, \& Downs, 1995). However, under some circumstances, striving for immediate self-esteem gains may have often been a less-than-optimal adaptive response. Although we believe that the typical state of affairs was for the self-evaluation motives underlying the information and action components to work together, it is also the case that these could have occasionally been working at cross-purposes. What happened when these motives were in conflict? In these cases, which motive was likely to "win?"

It makes sense that the continued activation of a particular motive depended, in part, on the type of existing information available. For example, when the individual was highly certain about the possession of an attribute, then gathering additional diagnostic information would not be efficient. Thus, in this situation, the self-assessment motive would not be activated or would not be powerful. Instead, the self-verification motive would emerge as the more powerful of the two motives, and behavior designed to confirm the attribute in question clearly would be the more likely response. This self-verification would help the individual to resist unwarranted changes in self-knowledge, thus maintaining the integrity of the self-concept. Conversely, in the absence of certainty about a given attribute, neither the self-assessment nor the self-improvement motive would be more powerful. Instead, both of these motives can prompt the individual to master the contingencies necessary for informed and fruitful transactions with the social environment. However, even under these circumstances, the long-term demands for veridical, improving, and positively verifying information might dictate that unflattering information about the self (i.e., nonenhancing or verifying of negative attributes--e.g., 1 can't do this") be uncovered or disclosed in the short run. As is often said, the first step to rectifying a problem is the admission that a problem exists, and that initial admission is often emotionally costly.

More generally, we hypothesize that the activation of a particular motive relative to others depends on the trade-off between the worth of the veridical (i.e., high diagnosticity) information and its emotional costs (Strube, 1990). For example, what if negative information about a person's capabilities pertained to an important domain (e.g., being terrible at crucial gather- 
ing or hunting tasks)? In this case, admitting to the veridicality of the information could bring about unbearable affective consequences (e.g., depression to the effect of malfunctioning). Conversely, neglecting the information via dismissal, denial, or even self-deception could allow the individual to function effectively in daily tasks (e.g., by focusing attention on and sharpening alternate skills) but could also cause other irreparable damage (e.g., eventual social exclusion). In this case, a pragmatic cost-benefit analysis may have been required before an individual opted to be influenced by either the self-protection motive or the self-assessment and self-improvement motives.

Another consideration is the possibility that the organism's response was contingent on the modifiability of the attribute under consideration (Dunning, 1995). That is, an individual might be predisposed to accept high diagnosticity feedback regarding skills that are thought to be modifiable through practice, and his or her self-improvement motive would clearly be applicable in this circumstance. However, the individual might have opted to pursue self-protection when attributes were thought to be unmodifiable. The relative worth of information, as perceived by the organism, might also have been contingent on the organism's affective state. For example, if the individual's self-esteem had suffered a recent blow, the individual may be particularly attuned to the immediate needs for self-protection and thus would avoid high diagnosticity, but negative, information.

The utility of the various motives in responding to challenges in the person-environment fit can also depend on the availability of cognitive resources (Paulhus, 1993; Swann, Hixon, Stein-Seroussi, \& Gilbert, 1990). For example, sometimes the external challenge to one of our ancestors (e.g., a public provocation by other group members) may have required an expedient response. In such cases, a deliberate analysis of the situation may have had deleterious consequences for the individual, as the others threatened immediate action. Instead, candid self-enhancement (e.g., display of physical prowess, vocal denial of the charges, verbal attack of the offensive opponent) would take precedence. At other times, as when the external challenge was amenable to a delayed response (planning to replace an ineffective leader), tactical self-enhancement (e.g., emphasizing one's ability to self-assess and self-improve) may have been a more appropriate motivation.

It is likely that other features of the social context were also crucial determinants of candid versus tactical self-enhancement. For example, tactical self-enhancement would be the more sensible alternative when one was accountable for her or his behavior to other group members or when one's behavior was easily verifiable by others (Felson, 1993). Tactical selfenhancement would also be the more adaptive response when one presented the self to closely affiliated others. Interpersonal closeness might have inhibited candid self-enhancement because, given their familiarity with the individual's record, close others limit the individual's opportunities to engage in self-aggrandization (Sedikides, Campbell, Reeder, \& Elliot, 
1998; Tice, Butler, Muraven, \& Stillwell, 1995). Alternatively, the individual may not be selfserving in interactions with close others because of kin selection pressures. This form of cooperation refers to altruistic behavior to, ward kin that results in their having a selective advantage (Hamilton, 1964).

In the cases described so far, we have treated the results of the antagonistic competition among selfevaluative motives very simply: One motive remains active while the others are suppressed. Of course, this suppression need not be permanent. Instead, an individual may prioritize motives and choose to pursue one course of action immediately while planning to satisfy the other motive at a later date. For example, we have argued that the symbolic self was embedded in a social context and was defined with reference to that context. Accordingly, pursuit of the candid self-enhancement motives cannot proceed without restraint: An individual needs to also be concerned about the feedback that is received from others. Although an individual might act selfishly from time to time, in a social context, consistently selfish behavior is likely to bring social approbation, leading to negative affect. Hence, an individual might delay the implementation of selfish motives until more appropriate circumstances are available (e.g., one can execute a selfish behavior without being seen).

Other situations may have similarly involved a conflict between candid selfenhancement objectives and long-term tactical self-enhancement objectives. For example, because it denotes acceptance of another individual's superiority, willingly giving up control to a more powerful group member may seem maladaptive. However, control relinquishment may have been an effective (i.e., conflict-free) strategy for satisfying long,term objectives (e.g., gaining acceptance; see Rothbaum, Weisz, \& Snyder, 1982). Likewise, expressing pessimism for one's impending performance may have appeared self-defeating, but this strategy safeguarded the individual against the debilitating effects of anxiety and thus maximized the achievement of long, term self-enhancing objectives (e.g., task success; see Norem \& Cantor, 1986).

\section{SELF-EVALUATION MOTIVES GONE AWRY}

We have argued that self-evaluation motives served critical functions and contributed substantially to our human ancestors' ability to adapt to their environment. Undoubtedly, though, there were instances of malfunctioning in motive operation. This observation is not threatening to our evolutionary argument. As is illustrated by the example of sickle-cell anemia, adaptations that increase overall species fitness in a particular environment can have negative consequences for specific individuals or can be maladaptive under different environmental circumstances. 
Nonetheless, it is useful to consider some of the ways in which the motives that serve the symbolic self go awry. Of course, one way in which these motives can go awry is when they become too powerful and overly dominate the thoughts, actions, and emotions of individuals. For example, excessive pursuit of self-enhancement could ultimately be nonadaptive, as it could lead the organism to take unnecessary risks (Baumeister, Heatherton, $\&$ Tice, 1993). Excessive pursuit of selfprotection (e.g., denial) could temporarily maintain psychological health, but it could also render the individual incapable of meeting long-term challenges by causing individuals to avoid potentially useful feedback. Additionally, excessive pursuit of both self-enhancement and self-protection would probably alienate the individual from other group members, because they would make negative inferences about the individual. Among these inferences would be that the individual was conceited, uncooperative, and hostile (Baumeister, Smart, \& Boden, 1996) and, hence, unfit for group life. Because group life seemed to be an adaptive trait for human ancestral species members, exclusion from the group would have reduced the reproductive fitness of the excluded individual.

Likewise, the excessive action of the learning and homeostatic motives could have disastrous repercussions for the individual and also for the group. An excessive emphasis on self-assessment could obstruct, if not paralyze, individual and group action. An excessive emphasis on self-improvement could pose strenuous demands on the individual and create an unduly competitive group environment. In the same vein, an excessive emphasis on selfverification would undermine the dynamism of the individual and would reinforce apathy at both the individual and group level. An overemphasis on self-improvement might be similarly counterproductive, causing individuals to waste time attempting to improve skills that are already near enough to optimum levels that continued improvement would not significantly increase the survival and reproduction chances of the individual or group.

Of course, insufficient exercise of the motives could also have had deleterious consequences. An individual engaging in suboptimal selfenhancement or selfprotection could place the self at risk for psychopathology. In addition, the individual could be seen as a meek and dysfunctional group member, one that lacks potential; a demotion in group ranks would be a likely outcome of the development of such perceptions. Similar social disapprobation, and consequent lowered reproductive fitness, is a likely result of deficiencies in the operation of the other self-evaluation motives. Insufficient pursuit of self-assessment or self-improvement could cause an individual to be viewed as an unproductive group member, lowering his or her social rank. Insufficient pursuit of self-verification could result in apparently inconsistent behaviors. This would cause the individual to be perceived as inconsistent, unreliable, and untrustworthy. Obviously (current American politicians notwithstanding), these individuals would tend to be low in social rank in the group. 
In summary; we speculate that nonoptimal action of the self-evaluation motives, either excessive action or insufficient action, probably proved costly to human ancestor species members. We further speculate that this nonoptimal activity contributed to a weak, uncertain, and confused symbolic self; inhibited good person-environment fit; and hampered the harmony of group life. Interactive relations among the motives exacerbated these costs: Malfunction of any given motive had the potential to block the feedback loops among the motives. Disarray of the self-system would be the result.

\section{CONCLUSION}

In previous work (Sedikides \& Skowronski, 1997; Skowronski \& Sedikides, 1999), we argued for the symbolic self as an evolutionary adaptation. In the present chapter, we have further advanced our thinking by advocating the thesis that three classes of self-evaluation motives-valence, learning, and homeostatic-were secondary adaptations that evolved to facilitate the smooth functioning of the symbolic self.

We argue that the self-evaluation motives served specialized cognitive and affective functions and that these motives evolved in response to specific environmental challenges. We conceptualize the motives as innate learning modules (Pinker, 1997). At the same time, we are obligated to express skepticism for this view, because we are as yet unable to provide credible neuroanatomical evidence for this proposition.

Despite the domain specificity of the self-evaluation motives, we also argue for their dynamic interplay. This idea is consistent with the speculations of some anthropologists who argue that the mind of our evolutionary ancestors (starting with Homo erectus) was characterized by the constant flow of knowledge among the various modules making up the mind. Cognitive fluidity was the norm rather than the exception (Mithen, 1996). Through its reflexive and executive capacity, the symbolic self could have constantly regulated the emergence, suppression, or synergistic action of the motives.

We hope that our speculative exposition into the evolutionary origins and functions of the self-evaluation motives will eventually be supplemented by empirical evidence. Research validating the notion that the motives are secondary adaptations will need to clarify the operations of the motives (e.g., V.Ihat are the conditions that trigger the activation of each motive? What are the rules that govern motive interplay?) and to document the specific evolutionary problems that were solved by the evolution of the motives. 


\section{REFERENCES}

Baumeister, R. E (1998). The self. In D. T. Gilbert, S. T. Fiske, \& G. Lindzey (Eds.), The handbook of social psychology (Vol. 1, pp. 680-740). New York: Oxford University Press.

Baurneister, R. E, Heatherton, T. E, \& Tice, D. M. (1993). When ego threats lead to self-regulation failure: Negative consequences of high self-esteem. Journal of Personality and Social Psychology, 64, 141-156.

Baumeister, R. E, Smart, L., \& Boden, J. M. (1996). Relation of threatened egotism to violence and aggression: The dark side of high self-esteem. Psychological Review, 103, 5-33.

Belk, R. W. (1988). Possessions and the extended self. Journal of Consumer Research, 15,139-168.

Breckler, S. j., \& Greenwald, A. G. (1986). Motivational facets of the self. In R. M. Sorrentino \& E. T. Higgins (Eds.), Handbook of motivation and cognition: Foundations of social behavior (Vol. 1, pp. 145-164). New York: Guilford Press.

Brown, J. D., \& Dutton, K. A. (1995). Truth and consequences: The costs and benefits of accurate self-knowledge. Personality and Social Psychology Bulletin, 21, 1288-1296.

Buss, D. M. (1996). The evolutionary psychology of human social strategies. In E. T. Higgins \& A. W Kruglanski (Eds.), Social psychology: Handbook of basic principles (pp. 3-38). New York: Guilford, Press.

Cantor, N., Markus, H., Niedenthal, R, \& Nurius, R (1986). On motivation and the self-concept. In R. M. Sorrentino \& E. T. Higgins (Eds.), Motivation and cognition: Foundations of social behavior (pp. 96-127). New York: Guilford Press.

Caporael, L. R. (1997). The evolution of truly social cognition: The core configurations model. Personality and Social Psychology Review, 1, 276-298.

Caporael, L. R., \& Brewer, M. B. (1991). Reviving evolutionary psychology: Biology meets society. Journal of Social Issues, 47, 187-195.

Carver, C. S., \& Scheier, M. E (1990). Principles of self-regulation: Action and emotion. In E. T Higgins \& R. M. Sorrentino (Eds.), Handbook of motivation and cognition: Foundations of social behavior (Vol. 2, pp. 3-52). New York: Guilford Press.

Cheyney, D. L., \& Seyfarth, R. M. (1992). Precis of how monkeys see the world. Behavioral and Brain Sciences, 15, 135-182.

Dunbar, R. 1. M. (1992). Neocortex size as a constraint on group size in humans. Journal of Human Evolution, 20, 469-493.

Dunbar, R. 1. M. (1993). Coevolution of neocortical size, group size, and language in humans. Behavioral and Brain Sciences, 16, 681-735.

Dunning, D. (1995). Trait importance and modifiability as factors influencing selfassessment and self-enhancement motives. Personality and Social Psychology Bulletin, 21, 1297-1306.

Emmons, R. A. (1989). The personal striving approach to personality. In L. A. Pervin (Ed.), Goal concepts in personality and social psychology (pp. 87-126). Hillsdale, NJ: Erlbaum. 
Fazio, R. H., Eff-rein, E. A., \& Falender, V J. (1981). Self-perceptions following so, cial interactions. Journal of Personality and Social Psychology, 41, 232-242.

Felson, R. B. (1993). The (somewhat) social self.. How others affect self-appraisals. In J. Suls (Ed.), Psychological perspectives on the self (Vol. 4, pp. 1-26). Hillsdale, NJ: Erlbaum.

Fox, R. (1980). The red lamp of incest. New York: Dutton.

Gallup, G. G., Jr. (1992). Levels, limits and precursors to self-recognition: Does ontogeny recapitulate phylogeny? Psychological Inquiry, 3, 117-118.

Gallup, G. G., Jr., \& Suarez, S. D. (1986). Self-awareness and the emergence of mind in humans and other primates. In J. Suls \& A. G. Greenwald (Eds.), Psychological perspectives on the self (Vol. 3, pp. 3-26). Hillsdale, NJ: Erlbaum.

Gibson, K. R. (1986). Cognition, brain size, and the extraction of embedded food resources. In J. G. Else \& P. C. Lee (Eds.), Primate ontogeny, cognition and social behavior (pp. 93-103). Cambridge, England: Cambridge University Press.

Greenwald, A. G. (1980). The totalitarian ego: Fabrication and revision of personal history. American Psychologist, 35, 603-618.

Hamilton, W. D. (1964). The genetic evolution of social behavior, Part 1 and 11. Journal of Theoretical Biology, 7, 1-52.

Higgins, E. T (1987). Self-discrepancy: A theory relating self and affect. Psycholog ical Review, 94, 319-340.

Higgins, E. T (1996). The "self-digest": Self-knowledge serving self-regulatory functions. Journal of Personality and Social Psychology, 71, 1062-1083.

Hyatt, C. W, \& Hopkins, W. D. (1994). Self-awareness in bonobos and chimpanzees: $A$ comparative perspective. In S. T. Parker, R. W. Mitchell, \& M. L. Boccia (Eds.), Self-awareness in animals and humans: Developmental perspectives (pp. 248-253). New York: Cambridge University Press.

Isaac, G. (1981). Stone age visiting cards: Approaches to the study of early land-use patterns. In 1. Hodder, G. Isaac, \& N. Hammond (Eds.), Patterns of the past (pp. 131-155). Cambridge, England: Cambridge University Press.

Kato, K., \& Markus, H. R. (1993). The role of possible selves in memory. Psychologia: An International Journal of Psychology in the Orient, 36, 73-83.

KihIstrom, J. E, \& Cantor, N. (1984). Mental representations of the self. In L. Berkowitz (Ed.), Advances in experimental social psychology (Vol. 17, pp. 1-47). New York: Academic Press.

KihIstrom, J. E, \& Klein, S. B. (1994). The self as a knowledge structure. In R. S. Wyer, Jr., \& T K. Srull (Eds.), Handbook of social cognition (Vol. 1, pp. 153-208). Hillsdale, NJ: Eribaum.

Kunda, Z. (1990). The case for motivated reasoning. Psychological Bulletin, 108, 480-498.

Leary, M. R., \& Tambor, E. S., Terdal, S. K., \& Downs, D. L. (1995). Self-esteem as an interpersonal monitor: The sociometer hypothesis. Journal of Personality and Social Psychology, 68, 518-530.

Lecky, P. (1945). Self-consistency: A theory of personality. New York: Island Press. 
Lewis, M. (1992). Will the real self or selves stand up? Psychological Inquiry, 3, 123-124.

Markus, H. (1983). Self-knowledge: An expanded view. journal of Personality, 51, 543-565.

Markus, H. R., \& Kunda, Z. (1986). Stability and malleability of the self-concept. Journal of Personality and Social Psychology, 51, 858-866.

Maryanski, A., \& Turner, J. H. (1992). The social cage: Human nature and the evolution of society. Stanford, CA: Stanford University Press.

McGuire, W J., McGuire, C. V., \& Winton, W (1979). Effects of household sex composition on the salience of one's gender in the spontaneous self-concept. Journal of Experimental Social Psychology, 15, 77-90.

Milton, K. (1988). Foraging behavior and the evolution of primate intelligence. In R. Byrne \& A. Whiten (Eds.), Machiavellian intelligence: Social expertise and the evolution of intellect in monkeys, apes and humans (pp. 285-305). Oxford, England: Oxford University Press.

Mithen, S. (1996). The prehistory of the mind: The cognitive origins of art, religion, and science. London: Thames \& Hudson.

Norem, J. K., \& Cantor, N. (1986). Anticipatory and post hoc cushioning strategies: Optimism and defensive pessimism in "risky" situations. Cognitive Therapy and Research, 10, 347-362.

Paulhus, D. L. (1993). Bypassing the will: The automatization of affirmations. In D. M. Wegner \& J. M. Pennebaker (Eds.), Handbook of mental control (pp. 573-587). Englewood Cliffs, NJ: Prentice-Hall.

Pinker, S. (1997). How the mind works. New York: Norton.

Rothbaum, E, Weisz, J. R., \& Snyder, S. S. (1982). Changing the world and chang, ing the self.. A two-process model of perceived control. Journal of Personality and Social Psychology, 42, 5-37.

Ryff, C. D., \& Singer, B. (1998). The contours of positive human health. Psychological Inquiry, 9, 1-28.

Sedikides, C., Campbell, W. K., Reeder, G., \& Elliot, A. J. (1998). The self-serving bias in relational context. journal of Personality and Social Psychology, 74, 378-386.

Sedikides, C., \& Skowronski, J. J. (1993). The self in impression formation: Trait centrality and social perception. Journal of Experimental Social Psychology, 29, 347-357.

Sedikides, C., \& Skowronski, J. J. (1995). On the sources of self-knowledge: The perceived primacy of self-reflection. Journal of Social \& Clinical Psychology, 14, 244-270.

Sedikides, C., \& Skowronski, J. J. (1997). The symbolic self in evolutionary context. Personality and Social Psychology Review, 1, 80-102.

Sedikides, C., \& Strube, M. J. (1995). The multiply motivated self. Personality and Social Psychology Bulletin, 21, 1330-1335.

Sedikides, C., \& Strube, M. J. (1997). Self-evaluation: To thine own self be good, to thine own self be sure, to thine own self be true, and to thine own self be 
better. In M. R Zanna (Ed.), Advances in experimental social psychology (Vol. 29, 209-269. New York: Academic Press.

Showers, C. (1992). Compartmentalization of positive and negative self-knowledge: Keeping bad apples out of the bunch. Journal of Personality and Social Psychology, 62, 1036-1049.

Shrauger, J. S., \& Schoenernan, T J. (1979). Symbolic interactionist view of the self-concept: Through the looking glass darkly. Psychological Bulletin, 86, 549573.

Skowronski, J. j., \& Carlston, D. E. (1982). Effects of previously experienced outcomes on the desire for choice. Journal of Personality and Social Psychology, 43, 689-701.

Skowronski, J. j., \& Sedikides, C. (1999). Evolution of the symbolic self. In D. H. Rosen \& M, C. Luebbert (Eds.), Evolution of the psyche (pp. 78-94). Westport, CT. Greenwood Publishing.

Strube, M. J. (1990). In search of self. Balancing the good and the true. Personality and Social Psychology Bulletin, 16, 699-704.

Strube, M. j., \& Roemmele, L. A. (1985). Self-enhancement, self-assessment, and self-evaluative task choice. Journal of Personality and Social Psychology, 49, 981-993.

Suarez, S. D., \& Gallup, G. G., Jr. (1981). Self-recognition in chimpanzees and orangutans, but not gorillas. Journal of Human Evolution, 10, 175-188.

Swann, W. B. (1983). Self-verification: Bringing social reality into harmony with the self. In J. Suls \& A. G. Greenwald (Eds.), Psychological perspectives on the self (Vol. 2, pp. 33-66). Hillsdale, NJ: Erlbaum.

Swann, W. B. (1990). To be adored or to be known? The interplay of selfenhancement and self-verification. In E. T. Higgins \& R. M. Sorrentino (Eds.), Handbook of motivation and cognition: Foundations of social behavior (Vol. 2, pp. 408-448). New York: Guilford Press.

Swann, W. B., Jr., Hixon, J. G., Stein-Seroussi, A., \& Gilbert, D. T. (1990). The fleeting gleam of praise: Cognitive processes underlying behavioral reactions to self-relevant feedback. Journal of Personality and Social Psychology, 59, 17-26.

Swann, W B., Wenflaff, R. M., Krull, D. S.' \& Pelham, B. W. (1992). Allure of negative feedback: Self-verification strivings among depressed persons. Journal of Abnormal Psychology, 101, 293-306.

Tanner, N. M. (1983). Hunters, gatherers, and sex roles in space and time. American Anthropologist, 85, 335-341.

Taylor, S. E., \& Brown, J. D. (1988). Illusion and well-being: A social psychological perspective on mental health. Psychological Bulletin, 103, 193-210.

Taylor, S. E., Neter, E., \& Wayment, H. A. (1995). Self-evaluation process. Personality \& Social Psychology Bulletin, 21, 1278-1287.

Taylor, S. E., Wayment, H. A., \& Carrillo, M. (1996). Social comparison, selfregulation, and motivation. In R. M. Sorrentino \& E. T. Higgins (Eds.), Handbook of motivation and cognition (Vol. 3, pp. 3-27). New York. Guilford Press. 
Tesser, A. (1988). Toward a self-evaluation maintenance model of social behavior. In L. Berkowitz (Ed.), Advances in experimental social psychology (Vol. 21, pp. 181-227). New York: Academic Press.

Thompson, C. R, Skowronski, J. J., Larsen, S. E, \& Betz, A. (1996). Autobiographical memory: Remembering what and remembering when. Malawah, NJ: ErIbaum.

'rice, D. M, Butler, J. L., Muraven, M. B., \& Stillwell, A. M. (1995). When modesty prevails: Differential favorability of self-presentation to friends and strangers. Journal of Personality and Social Psychology, 69, 1120-1138.

Tooby, j., \& DeVore, 1. (1987). The reconstruction of hominid behavioral evolution through strategic modeling. In W. G. Kinzey (Ed.), The evolution of human behavior (pp. 183-237). New York: State University of New York Press.

Trope, Y. (1983). Self-assessment in achievement behavior. In J. M. Suls \& A. G. Greenwald (Eds.), Psychological perspectives on the self (Vol. 2, pp. 93-121). Hillsdale, NJ: Erlbaum.

Trope, Y. (1986). Self-enhancement and self-assessment in achievement behavior. In R. M. Sorrentino \& E. T Higgins (Eds.), Handbook of motivation and cognition: Foundations of social behavior (Vol. 1, pp. 350-378). New York: Guilford Press.

Wilson, D. S. (1998). Hunting, sharing, and multilevel selection: The toleratedtheft model revisited. Current Anthropology, 39, 73-97.

Wilson, D. S., \& Sober, E. (1994). Reintroducing group selection to the human behavioral sciences. Behavioral and Brain Sciences, 17, 585-654. 